\title{
Validation of the Greek version of the Problematic Internet Use Questionnaire - Short Form (PIUQ- SF-6)
}

\author{
Panagoula Aivali ${ }^{1}$, Vasiliki Efthymiou², Artemis K. Tsitsika ${ }^{3}$, Dimitrios Vlachakis $^{2,4,5}$, George P. Chrousos ${ }^{2}$, \\ Christina Kanaka-Gantenbein ${ }^{6}$, Flora Bacopoulou ${ }^{2} \rrbracket$
}

\begin{abstract}
${ }^{1}$ Postgraduate Course of Science of Stress and Health Promotion, School of Medicine, National and Kapodistrian University of Athens, Athens, Greece

${ }^{2}$ University Research Institute of Maternal and Child Health \& Precision Medicine and UNESCO Chair on Adolescent Health Care, National and Kapodistrian University of Athens, Aghia Sophia Children's Hospital, Athens, Greece

${ }^{3}$ Adolescent Health Unit, Second Department of Pediatrics, School of Medicine, National and Kapodistrian University of Athens, "P. \& A. Kyriakou" Children's Hospital, Athens, Greece

${ }^{4}$ Laboratory of Genetics, Department of Biotechnology, School of Applied Biology and Biotechnology, Agricultural University of Athens, Athens, Greece

${ }^{5}$ Lab of Molecular Endocrinology, Center of Clinical, Experimental Surgery and Translational Research, Biomedical Research Foundation of the Academy of Athens, Athens, Greece

${ }^{6}$ Division of Endocrinology, Diabetes and Metabolism, Center for Rare Pediatric Endocrine Diseases, First Department of Pediatrics, School of Medicine, National and Kapodistrian University of Athens, Aghia Sophia Children's Hospital, Athens, Greece Competing interests: PA none; VE none; AKT none; DV none; GPC none; CKG none; FB none
\end{abstract}

\section{Abstract}

Internet is a necessary tool of everyday routine, however, concerns about the development of abnormal behaviours in relation to its use by adolescents are constantly growing. The need of brief screening tools for problematic internet use in teenagers in Greece is imperative. The purpose of this study was to validate the 6-item short form of the Problematic Internet Use Questionnaire (PIUQ-SF-6) in a Greek sample of adolescents. The sample consisted of 200 adolescents (55.0\% males, $61.6 \%$ high school students, $38.4 \%$ junior high school students) who completed the study's questionnaires i.e., a demographic questionnaire, the PIUQ-SF-6, the Young's Diagnostic Questionnaire (YDQ) and the Adolescent Computer Addiction Test (ACAT). The internal consistency of the Greek version of PIUQ-SF-6 was sufficient and acceptable (Cronbach's alpha coefficient $\mathrm{a}=0.80$ ). Confirmatory Factor Analysis was significant, and goodness-of-fit was adequate. For establishing convergent validity, Pearson's and Spearman's correlation coefficients were calculated between the PIUQ-SF-6 and ACAT scales and Receiver Operating Characteristic (ROC) analysis (between PIUQ-SF-6 and YDQ) indicated an excellent accuracy. The Greek version of the PIUQ-SF-6 demonstrated satisfactory psychometric properties (reliability and validity) and is recommended as a reliable screening tool for problematic internet use in Greek adolescents.

\section{Introduction}

Over the past decade the use of the internet has increased significantly and has become an integral part of our lives. Internet overuse is a global problem causing growing concern, which has led the scientific community to introduce terms such as "Problematic Internet Use" (PIU) or "Internet Addiction Disorder" (IAD). The term of IAD was first used by the New York based psychiatrist Ivan Goldberg (Dalal and Basu, 2002). The clinical psychologist Kimberly Young, in 1998, used the term

\section{Article history}

Received: 5 December 2020

Accepted: 4 February 2021

Published: 23 August 2021
"Addictive/ Pathological Internet use", based on common features with abnormal gambling (Young, 1998).

Young et al. found that internet addiction covers a number of behaviours and impulse control problems and can be classified into five different types: (i) Cyber sexual addiction - compulsive use of adult websites for cybersex and cyber porn, (ii) Cyber-relationship addiction - over involvement in online relationships, (iii) Net compulsions - obsessive online gambling, shopping, or online trading, (iv) Information overload -compulsive web surfing or database search, (v) Computer addiction

(C) 2021 Aivali et al; ; the authors have retained copyright and granted the Journal right of first publication; the work has been simultaneously released under a Creative Commons Attribution Licence, which allows others to share the work, while acknowledging the original authorship and initial publication in this Journal. The full licence notice is available at http://journal.embnet.org. 
- obsessive computer game playing (Young et al., 2000). Davis RA distinguished two types of pathological internet use, general pathological use of the internet that includes a general, multidimensional excessive use of the internet, and specific pathological use of the internet that includes those cases of users who are addicted to a specific function or application of internet (pornographic material and services, games, online trading, auctions, gambling, etc.) (Davis, 2001).

Various studies on internet addiction have been conducted internationally. In South Korea, internet addiction has become one of the most serious public health problems following the deaths of 10 teenagers from cardiorespiratory diseases in internet cafes (Choi, 2007). More than 210,000 children and adolescents, aged 6-19 years, are addicted, with $80 \%$ of them in need of treatment and 20\%-24\% in need of hospitalisation. At the same time, since 2009, more than a thousand specialists have been trained in 190 mental health structures (Ahn, 2007). In Taiwan, Tsai and Lin (2003) found that among 700 adolescents, $12.8 \%$ were addicted to the internet (Tsai and Linn, 2003). In a study conducted on a Korean sample of 1,573 adolescents, it was found that $1.6 \%$ of respondents were addicted to the internet (Kyunghee et al., 2006). In Iran, among 1,968 adolescents, 3.8\% were addicted (Gzassemzadeh, 2008). In Seoul, a survey of 903 adolescents showed that $10.7 \%$ were addicted and required further evaluation and intervention (Park et al., 2008).

In Greece, numerous studies have been conducted on adolescents' computer addiction. One of the first studies in a random sample of 897 adolescents in the large urban center of the capital of Athens, found 12.8\% of the adolescents with marginally healthy use of the internet, and only $1 \%$ with internet addiction. A key factor that determined the level of computer usage was the access points to it, as teenagers were found to spend more time online when at home or at internet cafes. In addition, users involved in social networking and video games showed a higher tendency to addiction (Tsitsika et al., 2009). A study in Thessaloniki, the second largest city in Greece, showed that in a sample of 278 high school students, 91\% were aware that the use of social networks can lead to addiction, while only $9 \%$ claimed that the use of social networks cannot lead to addiction. Moreover, $55 \%$ of the sample were personally aware of cases of students who had become addicted to social networks (Samaras, 2014). In the Greek province, the problem of internet addiction seemed more intense, as a survey in Thessaly in a sample of 2,200 high school students reported internet addiction in $8.2 \%$ of users, mainly in boys who played online games and visited frequented internet cafes (Siomos et al., 2008). Karapetsas et al., in a survey conducted in Volos in a sample of adolescents aged 13 to 15 years, found an internet addiction rate of $22 \%$, while gender was not found to be a determining factor (Karapetsas et al., 2012). A study conducted in the Greek island of Kos, in a sample of 1,270 adolescents aged $14-18$ years, showed that $7.2 \%$ of boys and $5.1 \%$ of girls were addicted to the internet (Fisoun et al., 2012). A survey in adolescents aged 13 to 18 years, in the areas of Attica, Halkidiki and Rhodes in Greece, showed a $12 \%$ percentage of addicted students with higher rates of addiction in boys (15\%) than girls (9\%). Almost all students had a computer with internet connection at home, while those who did not have a computer visited internet cafes to access the internet (Sofos et al., 2011). Another study conducted in 2010 in a sample of students aged 11, 13 and 15 years, throughout Greece, found that $15.5 \%$ of the adolescents were addicted to the internet and $5.5 \%$ were addicted to electronic games. Specifically, the percentage of students who used the computer for at least 3 hours daily on weekdays, increased with age; from $14.1 \%$ at 11 years to $25.8 \%$ at 13 years and $33.7 \%$ at 15 years. In addition, more boys (26.8\%) than girls $(21.9 \%)$ used the computer for at least 3 hours daily on weekdays (Kokkevi et al., 2010).

Therefore, the need of brief screening tools for PIU in teenagers in Greece is imperative. The purpose of this study was to validate the 6-item short form of the Problematic Internet Use Questionnaire (PIUQ-SF-6) in a Greek sample of adolescents.

\section{Materials, Methodologies and Techniques}

\section{Participants}

The study was conducted from July to September 2020. The sample was recruited from three Greek cities; Athens (the urban capital of Greece with more than $5,000,000$ residents), Nafplio (middle sized rural town with 33,356 citizens) and Nemea (small rural town with 6,483 citizens). The sample was set to be able to conduct factor analysis. According to the literature, the study sample should either follow the rule of 100, (Gorsuch, 1983; Kline, 1979), or five times higher than items (this means 30 subjects in the present study) (Hatcher, 1994), or at least 150 - 300 cases (Hutcheson and Sofroniou, 1999). Prior to study entry, students and their parents/ guardians were asked to provide written consent.

\section{Materials}

Participants were asked to declare few demographic characteristics such as sex, age, school class, parental educational level, and parental job status. Adolescents' habits related to internet use were assessed with four questions abouti) ownership or not of a personal computer (PC) they used, ii) hours spent online, iii) main reason of internet use, and iv) social media used. Adolescents were also asked to complete three questionnaires, the Problematic Internet Use Questionnaire-short form (PIUQ-SF-6), the Young's Diagnostic Questionnaire (YDQ) and the Adolescent Computer Addiction Test (ACAT).

Problematic Internet Use Questionnaire (PIUQ) : The PIUQ comprises three versions (18-item, 9-item, and 6-item), all having reliable factor structures, and proven validity across both online and written data collection 
methods in samples of different age groups (i.e., adults and adolescents) (Demetrovics et al., 2016). For the basic outcome of the study, the validation of a short and quick instrument to measure problematic internet use, the 6-item short form of the PIUQ (PIUQ-SF-6) was used. The original version of the PIUQ with 18 items was developed on a Hungarian sample (Demetrovics, 2008). Years later, the short 9-item version (PIUQ-9) was developed (Laconi et al., 2019) with an aim to create a brief, comprehensive, non-arduous screening tool given that previous version caused fatigue and desertion. This version was evaluated in nine European samples of internet users that included 154 Greek adults. Another shorter version was developed using 6 items with an aim to assess more impulsive populations in limited time (Demetrovics et al., 2016). The 3-factor structure has been retained in all versions: obsession, neglect, and control disorder. A 5-point Likert scale ("never", "rarely", "sometimes", "often", "always/almost always") was used to evaluate how much the given statements characterized the respondents. Scores range from 6 to 30, with higher scores indicating higher risk of PIU. In the original version of the PIUQ, Cronbach's alpha was 0.87 (obsession $\alpha=0.85$; neglect $\alpha=0.74$; control disorder $\alpha=0.76)$ (Demetrovics, 2008). For the shorter version PIUQ-9, internal consistency ranged from 0.81 (German subsample) to 0.90 (Turkish subsample) (Laconi et al., 2019). For the 6-item version PIUQ-SF-6 Cronbach's alpha was equal to $\alpha=0.77$ (Demetrovics et al., 2019). The test-retest correlation of the original PIUQ was 0.90 (Demetrovics et al., 2008).

Validation procedure: After obtaining permission from the developer to validate the PIUQ-SF-6 in a Greek population sample, the forward and back translation stage was carried out. Two bilingual translators, native speakers of Greek, translated the initial version of the PIUQ-SF-6 to the Greek language. They worked separately and each translator produced a written record of a translated version. Afterwards, the principal investigator unified the two translations into a single version since there were no significant differences between them. A third bilingual translator, native English speaker was recruited to translate backward the Greek version to the English language, without having ever read the original questionnaire. A three-person expert committee (including the principal investigator, a professor and a statistician experienced in cultural adaptation) supervised the translated versions and finalised the Greek version of the PIUQ-SF-6.

A pilot test in 15 participants was conducted to identify any confusing questions or meanings as well as suggestions for possible improvement. Moreover, during the pilot test the principal instigator counted the time needed for completion of the questionnaire (approximately 3 minutes). Reliability analysis, and more specifically Cronbach's alpha, was carried out in this phase to examine the internal consistency of the PIUQSF-6 which was found equal to $\mathrm{a}=0.72$, an acceptable value as it was higher than the threshold of 0.7 (De Vellis, 1991).

Young's Diagnostic Questionnaire (YDQ): For convergent validity and for Receiver Operating Characteristic (ROC) analysis the Young's Diagnostic Questionnaire (Young, 1996) was used, which is validated in the Greek population (Siomos et al., 2008). Young developed the YDQ from the pathological gambling DSM-IV criteria, using seven of ten DSM criteria and adding an eighth item (Young, 1996; Siomos et al., 2008). The YDQ consists of eight nominal questions (yes-or-no) regarding internet use. Participants who answer positively to five or more of the eight items are classified as addicted internet users, while the remaining participants are classified as normal internet users. The consistency of the Greek version of the YDQ was tested with Cronbach's alpha which was a $=0.72$ (Siomos et al., 2008).

Adolescent Computer Addiction Test (ACAT): A second tool used for convergent validity was the Adolescent Computer Addiction Test which was validated in Greek students in 2006 (Siomos et al., 2009) The ACAT is a 20-question tool with 5-point Likert type possible answers (1, not at all; 2 , rarely; 3 , occasionally; 4 , often; 5, always). After scoring the tool, four scales were constructed: Computer Addiction, Work Neglect, Social Life Neglect, Extreme Use. The ACAT has excellent test-retest reliability, internal consistency, and construct validity; the total scale reliability was $\mathrm{a}=0.93$, and the range for four scales was $\mathrm{a}=0.74$ to $\mathrm{a}=0.85$ (Siomos et al., 2009).

\section{Statistical analysis}

Absolute and relative frequencies were used to describe categorical variables such as demographic characteristics. Mean (M), standard deviation (SD) and median (Mdn) described continuous data. The internal consistency was carried out using Cronbach's alpha; values above 0.7 were considered acceptable (Cortina, 1993). Exploratory and Confirmatory Factor Analysis (EFA and CFA, respectively) were performed to examine the validated tool. For EFA, Varimax rotation was used. For CFA, chi-square test $\left(\mathrm{x}^{2}\right)$, comparative fit index (CFI), Tucker-Lewis index (TLI), root mean square error of approximation (RMSEA) and standardized root mean residual (SRMR) were computed to evaluate the model. The model can be considered satisfactory when the CFI and TLI values are higher than or close to 0.95 and still acceptable if the values are above 0.90 (Brown, 2006; Bentler and Bonett, 1980). An RMSEA value below 0.05 indicates excellent fit, a value around 0.08 indicates adequate fit, a value above 0.10 indicates poor fit and SRMR values below 0.10 indicate good fit (Brown, 2006; Browne and Cudeck, 1993). To check the convergent validity, Pearson's and Spearman rho correlation coefficients were computed. Convergent validity was considered an adequate instrument measuring the same construct when the correlation between PIUQ-SF-6 and ACAT was $>0.50$ (Abma et al., 2016). Also, ROC analysis 
and Area Under Curve (AUC) were established to check convergent validity as well $(0.7$ to 0.8 is considered acceptable, 0.8 to 0.9 is considered excellent, and more than 0.9 is considered outstanding) (Hosmer and Lemeshow, 2000).

Statistical analysis was performed using the SPSS version 25.0 (IBM Corp. Released 2017. IBM SPSS Statistics for Windows, Version 25.0. Armonk, NY: IBM Corp) and R Statistics software version 4.0.3 ( $\mathrm{R}$ Core Team, 2020), and the ROC curve was fit and analysed using the Lavaan package (Rosseel, 2012).

\section{Results}

A total of 200 adolescents aged 12-17 years completed the questionnaires. Participants' demographic and other characteristics are presented in Table 1.

Specifically, $55.0 \%(\mathrm{n}=110)$ of the respondents were male, while females constituted $45.0 \%$ of the sample ( $\mathrm{n}=90)$. Most students were in high school $(61.6 \%)$ while $38.4 \%$ were in junior high school. Almost 8 out of 10 participants had parents who were high school graduates or had a University degree. Almost 10 out of 10 fathers were employed, whereas 8 out of 10 mothers

Table 1. Demographic characteristics of the sample $(\mathrm{N}=200)$.

\begin{tabular}{|c|c|c|c|}
\hline Characteristic & & Absolute frequency & Relative frequency (\%) \\
\hline \multirow[t]{2}{*}{ Sex } & Male & 110 & 55.0 \\
\hline & Female & 90 & 45.0 \\
\hline \multirow[t]{2}{*}{ School Class } & Junior high school & 76 & 38.4 \\
\hline & High school & 122 & 61.6 \\
\hline \multirow[t]{5}{*}{ Paternal educational level } & Junior high school & 1 & 0.5 \\
\hline & High school & 80 & 40.4 \\
\hline & College/Trade school & 16 & 8.1 \\
\hline & University degree & 96 & 48.5 \\
\hline & Master/PhD & 5 & 2.5 \\
\hline \multirow[t]{5}{*}{ Maternal educational level } & Junior high school & 5 & 2.5 \\
\hline & High school & 68 & 34.3 \\
\hline & College/Trade school & 26 & 13.1 \\
\hline & University degree & 91 & 46.0 \\
\hline & Master/PhD & 8 & 4.0 \\
\hline \multirow[t]{2}{*}{ Does your father have a job? } & Yes & 196 & 99.5 \\
\hline & No & 1 & 0.5 \\
\hline \multirow[t]{2}{*}{ Does your mother have a job? } & Yes & 155 & 78.3 \\
\hline & No & 43 & 21.7 \\
\hline \multirow{3}{*}{$\begin{array}{l}\text { The Personal Computer that you } \\
\text { use: }\end{array}$} & Exclusively mine & 51 & 25.9 \\
\hline & Shared with other family members & 143 & 72.6 \\
\hline & I do not use at home & 3 & 1.5 \\
\hline \multirow{5}{*}{$\begin{array}{l}\text { How many hours a day do you use } \\
\text { the internet? }\end{array}$} & $1-2$ hours & 34 & 17.2 \\
\hline & 2-3 hours & 75 & 37.9 \\
\hline & 3-4 hours & 69 & 34.8 \\
\hline & More than 4 hours & 17 & 8.6 \\
\hline & I do not use at all & 3 & 1.5 \\
\hline \multirow{6}{*}{$\begin{array}{l}\text { What is the main reason you use } \\
\text { Internet? }\end{array}$} & To play videogames & 66 & 33.8 \\
\hline & To find information about homework & 22 & 11.3 \\
\hline & To chat with friends or other people & 74 & 37.9 \\
\hline & For online shopping & 3 & 1.5 \\
\hline & To download movies or songs & 24 & 12.3 \\
\hline & To be informed & 6 & 3.1 \\
\hline \multirow{6}{*}{$\begin{array}{l}\text { Social media that you use (multiple } \\
\text { choice question) }\end{array}$} & Facebook & 180 & 32.6 \\
\hline & Instagram & 141 & 25.5 \\
\hline & Snapchat & 75 & 13.6 \\
\hline & Viber/WhatsApp & 129 & 23.4 \\
\hline & Twitter & 12 & 2.2 \\
\hline & TikTok & 15 & 2.7 \\
\hline 978 & & & $\begin{array}{r}\text { Page } 4 \text { of } \\
\text { not for indexir }\end{array}$ \\
\hline
\end{tabular}


Table 2. Factor loadings and descriptive statistics of three factors of the PIUQ-SF-6.

\begin{tabular}{|c|c|c|c|}
\hline & Obsession & Neglect & Control \\
\hline \multicolumn{4}{|l|}{ Disorder } \\
\hline 1. How often do you spend time online when you would rather sleep? & & 0.889 & \\
\hline $\begin{array}{l}\text { 2. How often do you feel tense, irritated, or stressed if you cannot use the Internet for as long as you } \\
\text { want to? }\end{array}$ & 0.916 & & \\
\hline $\begin{array}{l}\text { 3. How often does it happen to you that you wish to decrease the amount of time spent online but you } \\
\text { do not succeed? }\end{array}$ & & 0.365 & 0.640 \\
\hline 4. How often do you try to conceal the amount of time spent online? & & & 0.781 \\
\hline 5. How often do people in your life complain about spending too much time online? & & 0.774 & 0.373 \\
\hline $\begin{array}{l}\text { 6. How often does it happen to you that you feel depressed, moody, or nervous when you are not on the } \\
\text { Internet and these feelings stop once you are back online? }\end{array}$ & 0.689 & & 0.587 \\
\hline Eigenvalue & 1.71 & 1.44 & 1.43 \\
\hline Variance explained (\%) & 28.53 & 23.99 & 23.75 \\
\hline Mean & 2.19 & 2.51 & 2.25 \\
\hline Median & 2.00 & 2.50 & 2.00 \\
\hline Standard deviation & 0.78 & 0.88 & 0.78 \\
\hline
\end{tabular}

Values refer to loading after Varimax rotation, eigenvalue, percent of variance explained, mean, median, standard deviation.

Cronbach's alpha of the PIUQ-SF-6 was $\alpha=0.80$.

PIUQ-SF-6, Problematic Internet Use Questionnaire-Short Form (6-item)

were in employment. Nine in 10 students had a personal computer at home (25.9\% reported exclusive possession and $75.6 \%$ shared use with other family members). Regarding the hours they spent on the internet on a daily basis, $17.2 \%$ of the participants spent 1-2 hours, $37.9 \%$ 2-3 hours, $34.8 \%$ 3-4 hours, $8.6 \%$ more than 4 hours and the rest $1.5 \%$ did not own a computer and did not use internet at all. The main reasons for using internet were to chat with friends or other people (37.9\%) and to play games $(33.8 \%)$. The most popular social media were Facebook (32.6\%), followed by Instagram (25.5\%) and Viber/WhatsApp (23.4\%).

Exploratory Factor analysis: The EFA of PIUQSF-6 is presented in Table 2. Factor analysis showed good adaptability in the Obsession scale and mild adaptability in the Neglect and Control Disorder scales. The total variance explained by EFA was $76.27 \%$. The mean, median and standard deviation for Obsession were 2.19, 2.00 and 0.78 , for Neglect 2.51, 2.50 and 0.88, and for Control Disorder 2.25, 2.00 and 0.78 , respectively.

Regarding the internal consistency of the Greek version of the PIUQ-SF-6, Cronbach's alpha coefficient was $\mathrm{a}=0.80$ for the total scale (Table 2).

Confirmatory Factor analysis: The CFA of the PIUQ-SF-6 is presented in Table 3. Baseline model was found significant $\left(\chi^{2}=358.45, \mathrm{p}<0.001\right)$. The goodnessof-fit summary was adequate; $\mathrm{TLI}=0.88$; $\mathrm{CFI}=0.95$; SRMR $=0.04$. The only index that was not good enough is RMSEA which was 0.12 , slightly higher than 0.10 .

Convergent validity: To prove convergent validity, Pearson's and Spearman's correlation coefficients between the PIUQ-SF-6 and ACAT scales were calculated (Table 4).

Strongest correlations were found between Control Disorder and Extreme Use $(r=0.701, \mathrm{p}<0.001)$, Neglect
Table 3. Confirmatory Factor Analysis of the PIUQ-SF-6.

\begin{tabular}{llllll}
$\begin{array}{l}\text { Latent } \\
\text { Variables }\end{array}$ & $\begin{array}{l}\text { Latent } \\
\text { Variables }\end{array}$ & Estimate & $\begin{array}{l}\text { Std. } \\
\text { Error }\end{array}$ & z-value & $\mathrm{p}$ \\
\hline Obsession & Q2 & 0.59 & 0.06 & 9.49 & $<0.001$ \\
\hline & Q6 & 0.76 & 0.06 & 12.62 & $<0.001$ \\
\hline Neglect & Q1 & 0.54 & 0.07 & 7.26 & $<0.001$ \\
\hline & Q5 & 0.83 & 0.09 & 9.43 & $<0.001$ \\
\hline $\begin{array}{l}\text { Control } \\
\text { Disorder }\end{array}$ & Q3 & 0.53 & 0.08 & 6.77 & $<0.001$ \\
\hline & Q4 & 0.56 & 0.07 & 7.84 & $<0.001$ \\
\hline Chi-square & 358.45 & & & & \\
\hline Df & 15 & & & & \\
\hline P & $<0.001$ & & & & \\
\hline CFI & 0.95 & & & & \\
\hline TLI & 0.88 & & & & \\
\hline RMSEA & $0.12[0.07$, & & & & \\
{$[95 \% C I]$} & $0.17]$ & & & & \\
\hline SRMR & 0.04 & & & & \\
\hline AIC & 2972.26 & & & & \\
\hline BIC & 3021.66 & & & & \\
\hline SSABIC & 2974.14 & & & & \\
\hline
\end{tabular}

Q1 to Q6, questions of PIUQ-SF-6 as referred in Table 2.

PIUQ-SF-6, Problematic Internet Use Questionnaire-Short Form (6item); $d f$, degrees of freedom; CFI, Comparative Fit Index; TLI, TickerLewis Index; RMSEA; Root Mean Square Error of Approximation; 95\% CI, 95\% Confidence Interval; SRMR, Standardized Root Mean Square Residual; AIC, Akaike Information Criteria; BIC, Bayesian Information Criteria; SSABIC, sample size adjusted Bayesian Information Criteria. 
Table 4. Correlations between PIUQ-SF-6 and ACAT scales.

\begin{tabular}{llllllll} 
& $\mathbf{1}$ & $\mathbf{2}$ & $\mathbf{3}$ & $\mathbf{4}$ & $\mathbf{5}$ & $\mathbf{6}$ & $\mathbf{7}$ \\
\hline 1.Obsession§ & 1 & $0.491^{* * *}$ & $0.574^{* * *}$ & $0.681^{* * *}$ & $0.609^{* * *}$ & $0.624^{* * *}$ & $0.570^{* * *}$ \\
\hline 2. Neglect & 1 & $0.608^{* * *}$ & $0.514^{* * *}$ & $0.510^{* * *}$ & $0.438^{* * *}$ & $0.682^{* * *}$ \\
\hline 3. Control Disorder & & 1 & $0.675^{* * *}$ & $0.664^{* * *}$ & $0.617^{* * *}$ & $0.701^{* * *}$ \\
\hline 4. Computer Addiction & & & 1 & $0.776^{* * *}$ & $0.712^{* * *}$ & $0.713^{* * *}$ \\
\hline 5. Work neglect & & & & 1 & $0.718^{* * *}$ & $0.641^{* * *}$ \\
\hline 6. Social life neglect & & & & & 1 & $0.564^{* * *}$ \\
\hline 7. Extreme use & & & & & 1
\end{tabular}

${ }^{* * * *} p<0.001 ; * * * 0.01 ; * p<0.05$ (Pearson, $\$$ SSpearman rho correlation coefficients).

PIUQ-SF-6, Problematic Internet Use Questionnaire-Short Form (6-item); ACAT, Adolescent Computer Addiction Test

Table 5. ROC analysis and AUC between PIUQ-SF-6 and YDQ.

\begin{tabular}{llcccc}
$\begin{array}{l}\text { Test Result Vari- } \\
\text { ables }\end{array}$ & Area & Std. Errora & $\begin{array}{c}\text { Asymptotic } \\
\text { p-valueb }\end{array}$ & \multicolumn{2}{c}{ Asymptotic 95\% Confidence Interval } \\
\cline { 4 - 6 } & & & $<0.001$ & 0.70 & Lower Bound \\
\hline Obsession & 0.78 & 0.04 & 0.001 & 0.59 & 0.86 \\
\hline Neglect & 0.67 & 0.04 & $<0.001$ & 0.75 & 0.74 \\
\hline Control Disorder & 0.82 & 0.03 & $<0.001$ & 0.88 \\
\hline $\begin{array}{l}\text { PIUQ-SF-6 Total } \\
\text { Scale }\end{array}$ & 0.81 & 0.03 & &
\end{tabular}

The test result variables: Obsession, Neglect, Control Disorder, PIUQ-SF-6.

State variable: Addicted Internet users according to YDQ.

a. Under the nonparametric assumption

b. Null hypothesis: true area $=0.5$

ROC, Receiver Operating Characteristic; AUC, Area Under Curve; PIUQ-SF-6, Problematic Internet Use Questionnaire-Short Form (6-item); YDQ, Young's Diagnostic Questionnaire

and Extreme Use $(\mathrm{r}=0.682, \mathrm{p}<0.001)$, Obsession and Computer Addiction $(\mathrm{r}=0.381, \mathrm{p}<0.001)$.

To measure convergent validity, ROC analysis between PIUQ-SF-6 and YDQ was carried out (Table 5). For the total scale of PIUQ-SF-6, Control Disorder, and Obsession scale results indicated an excellent accuracy $(\mathrm{AUC}=0.81, \mathrm{p}<0.001,95 \% \mathrm{CI}[0.74,0.88], \mathrm{AUC}=0.82$, $\mathrm{p}<0.001,95 \%$ CI $[0.75,0.88]$ and $\mathrm{AUC}=0.78, \mathrm{p}<0.001$, $95 \%$ CI $[0.70,0.86]$ respectively). For the Neglect scale, results indicated an acceptable accuracy $(\mathrm{AUC}=0.67$, $\mathrm{p}$ $=0.001,95 \%$ CI $[0.59,0.75])$.

\section{Discussion}

Internet is a means of communication, entertainment and education that is constantly evolving, exerting a significant influence on the shaping of modern reality. While internet is a necessary tool of everyday routine, the concern for development of pathological behaviours in relation to its use is constantly growing. The negative effects on young people's physical health, due to the extensive screen time and sedentary lifestyle, internet addiction, excessive involvement with online games and social networking sites are of particular concern to the scientific community. In Greece, digital literacy has not come through a coordinated learning process but through commercial engagement, resulting in high levels of internet addiction (Sfakianakis et al., 2012).

The PIUQ-SF-6 is a comprehensive, brief tool that assesses three key factors in PIU; obsession (i.e., obsessive thinking about the internet and mental withdrawal symptoms caused by the lack of internet use), neglect (i.e., neglect of basic needs and everyday activities), and control disorder (i.e., difficulties in controlling internet use).

The basic criterion for the reliability of a scale is the Cronbach's alpha coefficient with acceptable values greater than 0.7 (DeVellis, 1991). With regards to the validation of PIUQ-SF-6, the questionnaire was checked for its internal consistency and was found sufficient and acceptable. For the initial version of the PIUQ-18, the Cronbach alpha was equal to 0.87 , while for the smaller version of the PIUQ-9, the internal consistency was 0.81 in the German sample and 0.90 in the Turkish sample. In our study, the CFI index was 0.95 and the SRMR index was 0.04 . Furthermore, in the initial version of PIUQ18 , the questionnaire contains 6 questions per factor, while in the PIUQ-9 version the questionnaire contains 3 questions per factor, and in the smaller PIUQ-SF-6 version it contains 2 questions per factor.

The main limitation of the study was that the sample was not representative of all areas in Greece, rural and urban. In addition, the study sample was relatively 
small compared to that of the original PIUQ-SF-6 questionnaire survey $(\mathrm{n}=5,005)$ (Demetrovics, 2016).

To conclude, the Greek version of the PIUQ-SF-6 demonstrated satisfactory psychometric properties (reliability and validity) and is recommended as a reliable screening tool for PIU in Greek adolescents. Future large surveys are needed to provide more in-depth knowledge about PIU in children and adolescents in Greece.

\section{Key Points \\ - Problematic Internet Use (PIU) is prevalent among teenagers. \\ - The need of brief screening tools for PIU in adolescents is imperative. \\ - The Greek version of the PIU Questionnaire-short form (PIUQ- SF-6) has satisfactory reliability and validity. \\ - The PIUQ-SF-6 is a reliable screening tool for PIU in Greek adolescents.}

\section{References}

1. Abma IL, Rovers M and van der Wees J (2016) Appraising convergent validity of patient-reported outcome measures in systematic reviews: constructing hypotheses and interpreting outcomes. BMC Research Notes 9, 226. http://dx.doi. org/10.1186/s13104-016-2034-2.

2. Ahn DH (2007) Korean policy on treatment and rehabilitation for adolescents' Internet addiction, in 2007 International Symposium on the Counselling and Treatment of Youth Internet Addiction. Seoul, Korea, National Youth Commission 49.

3. Bentler PM and Bonett DG (1980) Significance tests and goodness of fit in the analysis of covariance structures. Psychological Bulletin 88, 588-606. http://dx.doi.org/10.1037/0033-2909.88.3.588.

4. Brown TA (2006) Confirmatory Factor Analysis for Applied Research. New York: Guilford Organizational Research Methods. http://dx.doi.org/10.1177/1094428108323758.

5. Browne MW and Cudeck R (1993) Alternative ways of assessing model fit. In Bollen KA, Long JS (Eds.) Testing structural equation models 136-162. Newbury Park, CA: Sage.

6. Choi YH (2007) Advancement of IT and seriousness of youth Internet addiction. In 2007 International Symposium on the Counseling and Treatment of Youth Internet Addiction Seoul, South Korea: National Youth Commission.

7. Cortina JM (1993) What is coefficient alpha? An examination of theory and applications. Journal of Applied Psychology 78(1), 98.

8. Dalal PK and Basu D (2016) Twenty years of Internet addiction ... Quo Vadis? Indian J Psychiatry 58(1), 6-11. http://dx.doi. org/10.4103/0019-5545.174354.

9. Davis RA (2001) A cognitive-behavioral model of pathological Internet use. Computers in Human Behavior 17(2), 187-195. http://dx.doi.org/10.1016/S0747-5632(00)00041-8.

10. Demetrovics Z, Király O, Koronczai B, Griffiths MD, Nagygyörgy $\mathrm{K}$ et al. (2016) Psychometric properties of the Problematic Internet Use Questionnaire Short-Form (PIUQ-SF-6) in a nationally representative sample of adolescents. PLoS ONE 11(8) http://dx.doi.org/10.1371/journal.pone.0159409.

11. Demetrovics Z, Szeredi B and Rozsa S (2008) The three-factor model of Internet addiction: the development of the Problematic Internet Use Questionnaire. Behavior Research Methods 40, 563-74. http://dx.doi.org/10.3758/BRM.40.2.563.

12. DeVellis RF (1991) Scale development: Theory and applications Newbury Park, CA: Sage Publications.

13. Fisoun V, Floros G, Geroukalis D, Ioannidi N (2012) Internet addiction in the island of Hippocrates: the associations between Internet abuse and adolescent off-line behaviors. Child and Adolescent Mental Health 17(1), 37. http://dx.doi.org/10.1111/ j.1475-3588.2011.00605.x.

14. Ghassemzadeh L (2008) Prevalence of internet addiction and comparison of internet addicts and non-addicts in Iranian high schools Cyberpsychology \& Behavior 11(6),731-733. http:// dx.doi.org/10.1089/cpb.2007.0243.

15. Gorsuch RL (1983) Factor analysis (2nd ed.) Hillsdale, NJ: Erlbaum.

16. Hatcher L (1994) A Step-by-Step Approach to Using the SAS System for Factor Analysis and Structural Equation Modeling Cary. NC: SAS Institute, Inc.

17. Hosmer DW, Lemeshow S (2000) Applied Logistic Regression 2nd Ed. New York, John Wiley and Sons, pp. 160-164.

18. Hutcheson G, Sofroniou N (1999) The Multivariate Social Scientist: Introductory Statistics Using Generalized Linear Models Statistical Methods in Medical Research. Sage Publication Thousand Oaks. http://dx.doi.org/10.4135/9780857028075.

19. Karapetsas A, Fotis A and Zygouris N (2012) Adolescents and Internet Addiction: A research study of the occurrence. ENCEPHALOS 49, 67-72.

20. Kline P (1979) Psychometrics and Psychology. London: Academic Press.

21. Kokkevi A, Xanthaki M, Fotiou A, Kanavou E (2010) Computer and Internet Use Among Adolescents. Health Behaviour in School-aged Children 1-12. www.epipsi.gr

22. Kyunghee K, Enjung R, Mi-Young C, Eun-Ja Y, So-Young C et al. (2006) Internet addiction in Korean adolescents and its relation to depression and suicidal ideation: a questionnaire survey. International Journal of Nursing Studies 43 (2),185-92. http:// dx.doi.org/10.1016/j.ijnurstu.2005.02.005.

23. Laconi S, Urbán R, Kaliszewska-Czeremska K, Kuss DJ, Gnisci A et al. (2019) Psychometric evaluation of the nine-item Problematic Internet Use Questionnaire (PIUQ-9) in nine European samples of internet users. Frontiers in Psychiatry 10:136. http://dx.doi. org/10.3389/fpsyt.2019.00136

24. $\mathrm{R}$ Core Team (2020) R: A language and environment for statistical computing. R Foundation for Statistical Computing, Vienna, Austria. https://www.R-project.org/

25. Rosseel Y (2012) lavaan: An R package for structural equation modeling. Journal of Statistical Software 48(2), 1-36. http:// dx.doi.org/10.18637/jss.v048.i02.

26. Samaras A (2014) Social Networks and Addiction. Proceedings of the 3rd Panhellenic Educational Conference in Imathia, Greece.

27. Sfakianakis E, Siomos K, Floros G (2012) Internet addiction and other high-risk online behaviors. Livani Publishing Organization, Athens.

28. Siomos K, Dafouli E, Braimiotis D, Mouzas O, Angelopoulos N (2008) Internet addiction among Greek adolescent students. Cyberpsychology \& Behavior 11(6), 653-657. http://dx.doi. org/10.1089/cpb.2008.0088.

29. Siomos KE, Floros GD, Mouzas OD, Angelopoulos NV (2009) Validation of adolescent computer addiction test in Greek sample. Psychiatriki 20(3), 222-232.

30. Sofos A, Athanasiadis I, Diakos K, Douka A (2011) Internet addiction. Research in Greece. Proceedings of the 3rd Panhellenic Conference 826-836.

31. Park SK, Kim JY and Cho CB (2008) Prevalence of Internet addiction and correlations with family factors among South Korean adolescents. Adolescence 43(172), 895-909.

32. Tsai CC, Linn SS (2003) Internet addiction of adolescents in Taiwan: an interview study. Cyberpsychology \& Behavior 6(6), 649-52. http://dx.doi.org/10.1089/109493103322725432.

33. Tsitsika A, Critselis E, Kormas G, Filippopoulou A, Tounissidou $\mathrm{D}$ et al. (2009) Internet use and misuse: a multivariate regression analysis of the predictive factors of internet use among Greek adolescents. European Journal of Pediatrics 168(6), 655-665. http://dx.doi.org/10.1007/s00431-008-0811-1.

34. Young K, Pinster M, O'Mara J, Buchanan J (2000) CyberDisorders: The mental health concern for the new millennium. Cyberpsychology \& Behavior 3(5), 475-479 http://dx.doi. org/10.1089/cpb.1999.2.475

35. Young KS (1998) Internet Addiction: The emergence of a new clinical disorder. Cyberpsychology \& Behavior 1(3), 237-244. 